\title{
Factors Driving Foreign Women Entrepreneurship in China
}

\author{
Kit Shun Ng, Ping Ping Fu
}

\section{A B S T R A C T}

Objective: The objective of this article is to identify factors that drive and conditions that affect foreign women entrepreneurs in China. The emphasis is on the commonalities and differences between these women and women entrepreneurs in Western developed countries as reflected in the literature.

Research Design \& Methods: The study was designed to include both qualitative and quantitative data to allow better understanding of the topic. Interviews with foreign women entrepreneurs were first done to gain practical field insights which were then used with the information from the literature to develop the questionnaire for the survey for quantitative data.

Findings: The findings from the interviews and the survey from a very small sample show the key differences lie in internal factors like motivation and family-business orientation, but there are also similarities in terms of external characteristics, such as business nature, business size, financing source, etc. between foreign female entrepreneurs in China and those represented in studies. And the key challenges and learning reported by foreign female entrepreneurs in China are both related to culture.

Implications \& Recommendations: The article intends to fill the gap by offering some insights into foreign women entrepreneurs in China. Broader and in-depth empirical studies on this subject are needed to verify these initial findings, and stimulate interests in this important but neglected field.

Contribution \& Value Added: The originality of this work lies in contributing to some understanding that the gender plays role in entrepreneurship across cultures, particularly in China.
Article type: research article
entrepreneurship; women entrepreneur; female entrepreneur;
Keywords: China; foreign female entrepreneur; cross culture entrepreneurship; cross border/country entrepreneurship

JEL codes: L26, F22

Received: 16 June 2018 Revised: 30 September 2018 Accepted: 9 November 2018

\section{Suggested citation:}

Ng, K.S., \& Fu, P.P. (2018). Factors Driving Foreign Women Entrepreneurship in China. Entrepreneurial Business and Economics Review, 6(4), 49-69. https://doi.org/10.15678/EBER.2018.060403 


\section{INTRODUCTION}

Recent years have seen a significant increase in the numbers of entrepreneurs all over China thanks to the Chinese government's promotion of entrepreneurial spirit and active support for entrepreneurial endeavours. Globalisation accompanied by high levels of mobility also allows people to move where new opportunities are available. As a result, many people from developed countries are moving to emerging markets like China to seek new opportunities. However, historically, most cross-country entrepreneurship studies concentrated on immigrants from developing countries who moved to developed countries to seek opportunities due to external factors to survive.

Women entrepreneurs are globally recognized as the key engine for economic development and innovation (Davis \& Abdiyeva, 2012; Ascher, 2012; Noguera, Alvarez, \& Urbano, 2013; De Vita, Mari, \& Poggesi, 2014; Yadav \& Unni, 2016). Acs (2006), who chaired the research committee of Global Entrepreneurship Monitor (GEM) for two years, found that entrepreneurship driven by unmatched or unexploited business opportunities has a positive and significant effect on economic growth (Acs, 2006). GEM started to publish special topic report on women entrepreneurship (GEM's Women Report) since 2005, and Mastercard also released its inaugural Index of Women Entrepreneurs (MIWE) in 2017. The launch of these special global reports on women entrepreneurship indicates the growing importance of women in entrepreneurship and economic development in recent years.

However, the literature review has shown that women entrepreneurship research still has a long way to go. Scholars are calling for more research on this subject in emerging countries and the cross-country aspect (e.g., Minniti \& Naudé, 2010; De Vita et al., 2014; Yadav \& Unni, 2016; Elston \& Weidinger, 2015). Studies have identified different factors that influence women's decision to go into entrepreneurship. Ascher (2012) provided a conceptual model which consists of factors including motivation, demographics and family, social and economic environments, education and unemployment (Ascher, 2012). The latest Women's Entrepreneurship 2016/2017 report on Global Entrepreneurship Monitor (GEM) also found that gender gaps in entrepreneurship activity still persist in many countries (including China), regardless of the economic developmental stage (Kelley, Baumer, Cole, Dean, \& Heavlow, 2017), and research on women entrepreneurship has been neglected (Ascher, 2012). And there are a number of unique characteristics of women entrepreneurs, such as small business, industry nature, difficulties in accessing financing and social capital, (Minniti \& Naudé, 2010; Davis \& Abdiyeva, 2012; Lee \& Marvel, 2014) that are worth exploring. In China, in spite of the booming entrepreneurial activities and a more narrow gap between genders, women are still comparatively less active in entrepreneurship there (Kelley et al., 2017). The number of Chinese women entrepreneurs in China only account for roughly $20 \%$ of the total number of Chinese entrepreneurs (Fan, 2012). There has also been little research on Chinese women entrepreneurship, let alone foreign women entrepreneurs in China.

This article intends to get into this line of research by taking a mixed method approach to identify factors that drive and conditions that affect foreign women entrepreneurship in China. We will use interview data to gain the insights and then use qualitative data and literature to develop the survey instrument to collect quantitative data from a broader sample in order to compare the characteristics of foreign women entrepreneurs in China and those studied in developed countries. 


\section{LITERATURE REVIEW}

Research on women entrepreneurship was particularly neglected in the past (Ascher, 2012). However, in recent years, there has been an increasing number of research studies examining women entrepreneurs (Lee \& Marvel, 2014; Welsh, Kaciak, \& Thongpapanl, 2016). Yadav et al. (2016) reviewed 185 papers published in 12 well-established entrepreneurship journals about women entrepreneurship between the 1900s and 2016 and found that this domain was not a significant area of research until late 1990s or even early 2000s. Despite this faster growth in women entrepreneurship studies over the last two decades, the authors found that there is still a long way to go in terms of building a strong theoretical base for research in this area (Yadav \& Unni, 2016).

Besides, past studies on women entrepreneurship were conducted mostly in developed countries (Yadav \& Unni, 2016), so scholars call for more research studies on women entrepreneurs from emerging countries (De Vita et al., 2014; Yadav \& Unni, 2016) including China (Elston \& Weidinger, 2015). A recent literature review found that even women entrepreneurship studies were restricted i.e. they were conducted within some national boundaries (Yadav \& Unni, 2016). Therefore, Welsh et al. (2016) recommended more quantitative and crosscultural investigations across countries. Minniti et al. (2010) highlighted the importance of knowing the differences between and commonalities across individuals and across countries to deepen the understanding of female entrepreneurship (Minniti \& Naudé, 2010).

Most cross-cultural studies on women entrepreneurship, such as the literature review by De Vita et al. (2014), mainly concentrate on female immigrants from developing countries who were driven by financial factors to startup businesses in developed countries to survive. However, the research lessons so learnt might not necessarily be applicable to China where foreigners mostly come from developed countries. According to the China census of 2010, the Koreans, the Americans and the Japanese are among the top three groups of foreigners in China, in addition to those from Hong Kong, Macau and Taiwan. The total number of people from developed economies living in China is over 67\% ('6th China census statistic' 2010). Clearly, there exists a knowledge gap and an opportunity to understand more about women entrepreneurship from a foreigner's point of view in the cross-cultural perspective in the emerging China.

Yadav and Unni (2016) also studied 19 literature review articles published on women entrepreneurship from 1986 till May 2016. They pointed out a need to study the impact of factors like industry, family, culture and goal orientation and other external factors. Further, they observed that entrepreneurial processes such as venture financing, networks, firm performance, growth strategies, success factors and individual characteristics including intentions, motivations, decision models, etc. and the social forces impacting differences in gender behaviour among entrepreneurs also need to be investigated (Yadav \& Unni, 2016).

\section{Motivational Factors for Women Entrepreneurs}

Past research suggests that women from developed countries are motivated by pull (or opportunity-driven) factors, such as independence and autonomy and passion, whilst women from emerging countries tend to be pushed or forced into entrepreneurship (Davis \& Abdiyeva, 2012). Bruni et al. (2004) combined best-known classifications to draw up a typology of female entrepreneurs, namely 'aimless' young women, 'success-oriented' 
young women, 'strongly success-oriented' women, 'dualists', 'return workers', 'traditionalists' and 'radicals' (Bruni et al., 2004) (Table 1.)

Table 1. Typology of profiles of female entrepreneurs

\begin{tabular}{|l|l|}
\hline \multicolumn{1}{|c|}{ TYPE } & \\
\hline Aimless & Young females who enter entrepreneurship as a result of unemployment \\
\hline Success oriented & Young women who perceive entrepreneurial activity as a long-term strategy \\
\hline $\begin{array}{l}\text { Strongly success } \\
\text { oriented }\end{array}$ & $\begin{array}{l}\text { Women who perceive entrepreneurship as an opportunity for self-fulfillment or as a } \\
\text { means to overcome the 'glass ceiling' phenomenon }\end{array}$ \\
\hline Dualists & Females seeking flexibility to balance their family and job obligations \\
\hline Return workers & $\begin{array}{l}\text { Women who left their jobs to care for family duties and are still motivated to self-ful- } \\
\text { fillment outside their families }\end{array}$ \\
\hline Traditionalists & Women who have a strong family entrepreneurial tradition background \\
\hline Radicals & Women who initiate introducing more pro-female tendencies in society \\
\hline
\end{tabular}

Source: (Ascher, 2012).

These authors also identified three main types of barriers to women entrepreneurs:

1. socio-culture status of women's primary role are family and domestic responsibilities;

2. access to social capital like network of information or assistance due to gender exclusion; and finally;

3. access to capital (Bruni et al., 2004).

Ascher (2012) argued that no single motivation factor could drive women into entrepreneurship, and proposed a conceptual model that consisted of factors that may influence women to enter entrepreneurship, including motivation, demographic and family, social and economic environments, education and unemployment (Figure 1).

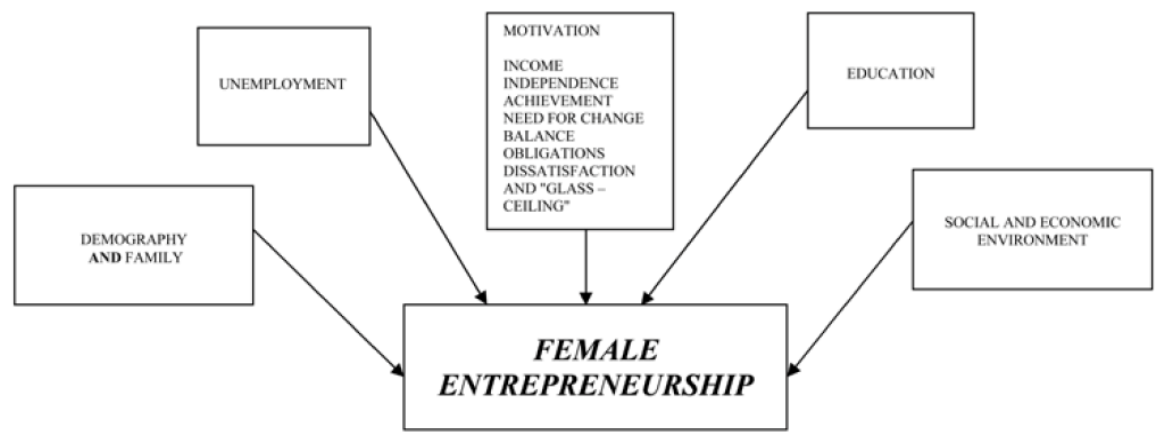

Figure 1. Ascher (2012)'s conceptual model

Source: (Ascher, 2012).

Ascher (2012) pointed out that past studies showed that women entrepreneurs tend to emphasize intrinsic and non-financial goals, such as independence and work-family balance, whilst men are more likely to be motivated by financial rewards. He also identified obstacles to women entrepreneurs at different stages of entrepreneurship processes, mainly the absence of benchmarking possibilities, lack of experience, lack of social capital and financial capital, lack of time due to family obligations, risk perception, gender discrimination to external financing, and gender stereotype issue, etc. Minniti and Naude (2010) also discussed 
that the lack of experience, lack of financial capital and start-up cost financing are the key issues and constraints to women entrepreneurs in developing countries. They pointed out that whereas there is not much difference in individual entrepreneurship motivation by entrepreneurial ability and the relative rates of return across developed and developing countries, social networks play a more important role in developing countries.

The words 'family' and 'women' are very closely related to each other even when it comes to entrepreneurship. There is a strong link between female entrepreneurship and the prevailing family systems (Welsh et al., 2016) in which identity enactment is observed by embedding habitual routines into their business practices (Lewis, Ho, Harris, \& Morrison, 2016). Researchers have concluded generally that women have different aspirations and non-pecuniary motives for pursuing entrepreneurship, as well as a greater need to gain flexibility for balancing work and family responsibilities (Minniti \& Naudé, 2010). Debates on work-family life balance are widespread in the contemporary society. A common view is that women's primary role is running the home and reproduction (Gherardi, 2015). Given the dual responsibilities of women, the work-family conflict constituted a key barrier to the success of women-owned businesses (Welsh et al., 2016).

Combining different reviews and literature reviews, we identified the following four characteristics to be universally common for women entrepreneurs and the businesses they run: (1) women tend to run smaller businesses with few employees; (2) their businesses mostly concentrate on retail, services, hospitality, and so on; (3) they experience higher challenges while accessing or getting formal financing; and (4) they lack professionally supported networks and business social capital (Minniti \& Naudé, 2010; Davis \& Abdiyeva, 2012; Lee \& Marvel, 2014).

Women's Entrepreneurship Report (WER, 2016/2017) of Global Entrepreneurship Monitor (GEM) provided in-depth quantitative insights into the global growth and characteristics of female entrepreneurship by grouping countries based on their economic development stages. WER 2016/2017 report found out that the highest participation in entrepreneurship among women was among $25-34$ and $35-44$ year olds. A similar phenomenon was reported in other reviews (Ascher, 2012). The report also presented a more detailed breakdown in terms of economic development levels. It found that around $60 \%$ women are engaged in the retail sector in factor-driven, factor-efficiency transition and efficiency-driven economies, whilst over $50 \%$ of women in innovation-driven economies dominate over men in the sectors of government, health, education, social services and accounting. Globally, women entrepreneurs are less likely to start businesses in the Information and Communication Technology (ICT) sector as compared to men (Kelley et al., 2017). The education level of women entrepreneurs is generally high, according to the report. Especially, in more developed countries such as North America and Europe, women entrepreneurs have the highest education rates or are even more highly educated than men entrepreneurs (Kelley et al., 2017). Nevertheless, countries are different. While these insights serve as good references, studies on female entrepreneurship in China are still essential to understanding what drives women to run their own businesses and how they do so in their country.

Thus, this article seeks to identify both internal (family-business orientation, goal orientation, motivation, etc.) and external (financing, business performance, success factors, etc.) factors that impact female foreigners coming to China to start businesses. The emphasis is on commonalities and differences as compared to other contemporary studies 
and reviews. The issues motivating foreign women entrepreneurs to select China to startup their businesses will also be examined. The overall goal is to provide preliminary understanding of women entrepreneurship in the cross-nation and cross-cultural context in China for future scholars conducting further in-depth studies.

\section{MATERIAL AND METHODS}

Reviewing gender and entrepreneurship literature published in 18 journals over a 30year period, Henry et al. (2016) identified the major methodological trend in this field. In the process, they suggested that future researchers of this subject should move from the traditional quantitative approach to a post-structural feminist approach involving more qualitative and innovative methodologies such as in-depth interviews, life histories and case studies (Henry, Foss, \& Ahl, 2016). Patterson et al. (2012) also endorses the need for applying a qualitative methodology to research into gender entrepreneurship (Patterson, Mavin, \& Turner, 2012). The present article adopts a mixed approach using interviews and online surveys to offer discovered insights into foreign women entrepreneurs in China. Specifically, questions we ask include: What are the factors that drive them into entrepreneurship in China? What are the conditions that make them startup a business in China? What are the key challenges and barriers to starting up and doing business in China? And what did they learn from doing business in China?

Since there is very limited precedent research on foreign women entrepreneurs in China, exploratory interview at the beginning enables us to identify what is important in the practical field. Together with the initial insights from the interview findings and the framework identified from the literature reviews, the survey is then designed to allow more practical relevance. Thus, our research methodology begins with interviewing female foreign entrepreneurs in China, mainly Shanghai, followed by an online survey with questions designed based on the interviews and the literature review.

\section{Interviews}

According to the latest census statistics of the Chinese government (6th China census statistic, 2010), most foreigners live in the Tier 1 big cities, such as Guangdong province, Shanghai and Beijing. Though Elston and Weidinger's empirical research found internationality to have a negative impact on entrepreneurial intention in the highly internationalised Shenzhen and Hong Kong as compared to rural China due to higher competition for resources (Elston \& Weidinger, 2015), language and cultural barriers suggest foreigner entrepreneurship activities should mostly concentrate in these Tier 1 cities.

Therefore, foreign women entrepreneurs in Shanghai were invited to join the interview given the first author's immediate access and personal network to foreign friends and many women entrepreneur community networks in Shanghai. The interviews were done over the phone, lasting an hour and a half on average. The interviews were recorded with the consent of the interviewees.

\section{Survey}

Following the interview, the survey with open-ended questions enabled us to reach a broader target group in a shorter period of time. The design of the survey questions leveraged the existing literature as well as the aforementioned interview findings. In order to 
capture descriptive answers and narratives for qualitative analysis and securing more indepth understanding of the subject, almost half of the survey was designed to allow open answers. Options were provided for those characteristics aimed at cross comparisons.

The survey was comprised of three parts. The first part of the survey sought to identify internal and external factors. As for internal factors, Ascher's (2012) conceptual model on motivational factors was adopted.

The following motivation factors were used in the survey: (1) Could not find a job; (2) Generate income; (3) For self-achievement; (4) Need for a change; (5) Pursuit of autonomy and independence; (6) Motherhood obligation; (7) Flexibility to balance family and work; (8) Dissatisfaction with the previous work environment; (9) Reaching the 'glass ceiling' in the present or previous company and (10) Family business or family entrepreneurial tradition. The social and economic environment was not included in the scope of the study. However, family-business orientation and goal-orientation questions were also added based on the initial interview findings.

Key challenges, business nature and size, industry sectors, financing sources, the startup process and key success factors were the external factors explored in the survey questions. Barriers and challenges identified based on the literature review were included in the survey, including the examination of the choice options (1) Lack of experience and skills; (2) Difficulty in acquiring investment or funding; (3) Lack of business social capital or network; (4) Family obligations and lack of time; (5) Gender discrimination; (6) Cultural differences; (7) Business scalability and (8) Talent attraction and retention.

The second part of the survey focused on how starting a business in China might be different from other countries and if those differences offer any learning or innovation to female entrepreneurs outside China. This part consisted mainly of open questions to allow more qualitative information. The last part was about their personal background and the reasons behind their coming to China, which offer important details to help readers better understand their intention and motivation or choices they had to make during their entrepreneurship decisions.

Our survey also tried to adopt Bruni et al. (2004)'s typology framework by identifying the top three reasons and motivations for women to start businesses, the reasons behind coming to China, the top three challenges faced, as well as personal background such as whether they had a job before the startup business, their age, marital status and children.

\section{Study Sample}

The samples for both interviews and surveys were pooled through personal networks and accessible women entrepreneurship communities in China. Four foreign female entrepreneurs were invited from different women entrepreneur communities in Shanghai. A total of 24 different female foreign entrepreneurs participated in the online survey through women entrepreneur community network.

Interviewee 1 (Itv-1) was an American who came to Hong Kong to study for a degree in Chinese. She was later hired by a big American multinational consumer goods company (P\&G) in China in 1991. She worked for big multi-national corporations until 2014 and then decided to startup her own business offering consulting services in China. She had been in China for nearly 30 years. She could speak fluent Chinese.

Interviewee 2 (Itv-2) was an Australian who followed her husband's job to move to China in 2014. She had worked in Australia in the HR field and then worked in her husband's company for about a year after she had moved to China. Then she left the job 
when she had her first baby. In 2016, she decided to do something on her own and started a project. The project focused on building a community network for women entrepreneurs in China where they learn and support each other as a group. She has been running this network for about 1.5 years now.

Interviewee 3 (Itv-3) was a Korean American. She was born in South Korea but was educated and grew up in the United States. She had followed her husband's job relocation and had lived and worked in different countries before China, such as Norway, South Korea and Singapore with Norway being the longest, about 14 years. She had her own business both in Norway and Singapore. She started her business again in China in 2016. The business is an online digital training content platform for senior care services. The business idea was actually conceived in Singapore where she had stayed for 1.5 years and registered her company there with a similar idea for the hospitality industry.

Interviewee 4 (Itv-4) was a young Finnish lady aged 31. She was born in China, However, having grown up and educated in Finland, she was raised with western values and culture. She came back to China in 2015 to run her family business. She took over her father's business $100 \%$, as CEO and Board director, right from day one after she had come back. Since then, she was running the company like her own business. The company was in the traditional manufacturing industry with over 20 years of history in China. Their main clients were from the construction sector.

\section{RESULTS AND DISCUSSION}

A total of 28 foreign entrepreneurs from 15 countries, including the four who were interviewed, and 24 participated in the survey. Out of 28 participants, 24 were from developed countries, four from South Africa, the Philippines, Ukraine and Mexico. The four interviewees and the majority (83\%) of the survey participants were located in Shanghai, but a few were based in other cities, including Beijing and Shenzhen.

\section{Typology Highly Associates With 'Strongly Success-Oriented' and 'Success-Oriented'}

By examining the backgrounds and motives of the interviewees, we found that the four interviewees fit into four of seven profiles identified by Bruni et al. (2004) as shown in Table 1 in the literature review. Each interview reported a different incentive to join entrepreneurship.

Itv-1 is obviously a 'strongly success-oriented' and 'radical' woman. Her motivation to startup her own business was 'I decided not to generate money for somebody else'

Itv-2 is both a 'return worker' and a 'radical' because she had left her career in her home country to follow her husband to China and left her job for her first baby. After the first baby had been born, she initiated a community network in support of female entrepreneurs as her future business.

Running a community platform for women entrepreneurs in Shanghai, Itv-2 also shared her observations concerning many female foreign entrepreneurs in her community who resonated entrepreneurial typologies such as 'return workers', 'strongly success-oriented' and 'dualists'.

'...people have moved into wanting to run their own business for different reasons. Some of them were like me, in that they had followed their partners to 
Shanghai because the partners got work here. So they had to leave their own careers back in their home country and come here and try to do something else. Some people were following a dream that they always had, and found a perfect opportunity to follow that dream to start a business. Some people felt a bit lost that they didn't' have a self-identity after they left the corporate role, so they were trying to form a new identity for themselves. Some people just wanted a change of career. And there were others...they were mothers who didn't fit into the corporate structure anymore...'

Itv-3 is a 'return worker' and a 'strongly success-oriented' woman who had also left her career and accompanied her husband to many countries. However, in each country, she started up her own business.

Itv-4 is an obvious 'traditionalist' who came back to China to take over her family traditional business. She also wants to startup her own business in the future.

By mapping the survey participants' motivation, the reason for coming to China, the prior job status (before China), age, and education, the survey showed that a majority of the participating female foreign entrepreneurs belong to 'strongly success-oriented' and 'success-oriented', with just a couple of them being 'return worker' or 'dualist' or 'traditionalist'. Detail findings of each of these surveyed factors are discussed in details as follow.

\section{Family-Work Balance Is Not the Major Motive}

Studies have suggested that women tend to put more emphasis on intrinsic goals or seek non-financial goals such as independence and work-family balance (Ascher, 2012). Itv-1 mentioned explicitly that she 'could be earning more money by working for someone else's company', but she chose to run her own business because she loves what she does now and the work variety related to her own business. And an interesting comment by Itv- 3 about the reason behind female entrepreneurs' desire to start a business is out of goodness to help the society was that:

'Many female entrepreneurs also start businesses out of the goodness of their hearts, idealism, wanting to help the society or something of that nature. And they may not necessarily think it through, whether it has the possibility of becoming a successful business.'

The survey confirms a similar finding that self-achievement and autonomy and independence stand out as the most important motivating factors, accounting for $65.2 \%$ and $52.5 \%$ respectively (Table 2 ).

While contemporary studies argue about dual responsibility and family factor as motivation for women entrepreneurship and a potential obstacle to their success, both our interview and survey however indicated differently, that 'work-family balance' and 'motherhood obligation' are among the least relevant factors. The interview reviewed that only one interviewee out of the four has this tendency of entrepreneurship enablement through family and motherhood responsibility.

The survey confirms that these two factors are not among the top 3 key motivation factors to enter entrepreneurship (Table 2). A half of them did not see any challenge of familywork balance. This finding was consistent with the view of the majority, who did not see 'family obligation and lack of time' as their major challenges (Table 5). In addition, more than 
$45 \%$ took business as more important than family. This result is different from the previous finding that women tend to seek work-family balance or flexibility as the motivation or goal to become an entrepreneur (Ascher, 2012; Lee \& Marvel, 2014). This seems to be due to the fact that most of the foreign women entrepreneurs who answered that these factors are least relevant, were still single (over 52\%) and did not have any children (over 78\%).

Table 2. Key priority of motivation to startup a business

\begin{tabular}{|l|c|c|c|c|}
\hline \multicolumn{1}{|c|}{ Key Priority } & $\mathbf{1}$ & $\mathbf{2}$ & $\mathbf{3}$ & N/A \\
\hline Could not find a job & 2 & 1 & 3 & 18 \\
\hline Generate Income & 8 & 3 & 5 & 8 \\
\hline Self-achievement & 15 & 3 & 5 & 1 \\
\hline Need for Change & 5 & 4 & 4 & 11 \\
\hline Autonomy and independence & 12 & 2 & 5 & 5 \\
\hline Motherhood Obligation & 2 & 1 & 2 & 19 \\
\hline Flexibility to balance Family and Work & 2 & 1 & 7 & 14 \\
\hline Dissatisfaction with present or previous job & 5 & 2 & 3 & 14 \\
\hline Dissatisfaction with previous work environment & 4 & 2 & 5 & 13 \\
\hline Reaching "glass ceiling" in present or previous company & 3 & 3 & 2 & 16 \\
\hline Family business or family entrepreneurial tradition & 2 & 1 & 2 & 19 \\
\hline Other & 4 & 1 & 0 & 19 \\
\hline
\end{tabular}

Source: own study.

Close to $74 \%$ of the participants did not select 'could not find a job' among their top 3 motivation factors. This echoes the findings of the GEM's WER 2016/2017 report. According to the report, women entrepreneurs from developed countries are not factor-driven but opportunity driven. This also is consistent with the reason cited that their coming to China was to 'startup a new business' or 'seek job opportunity'; over $62.5 \%$ in total (Figure 2).

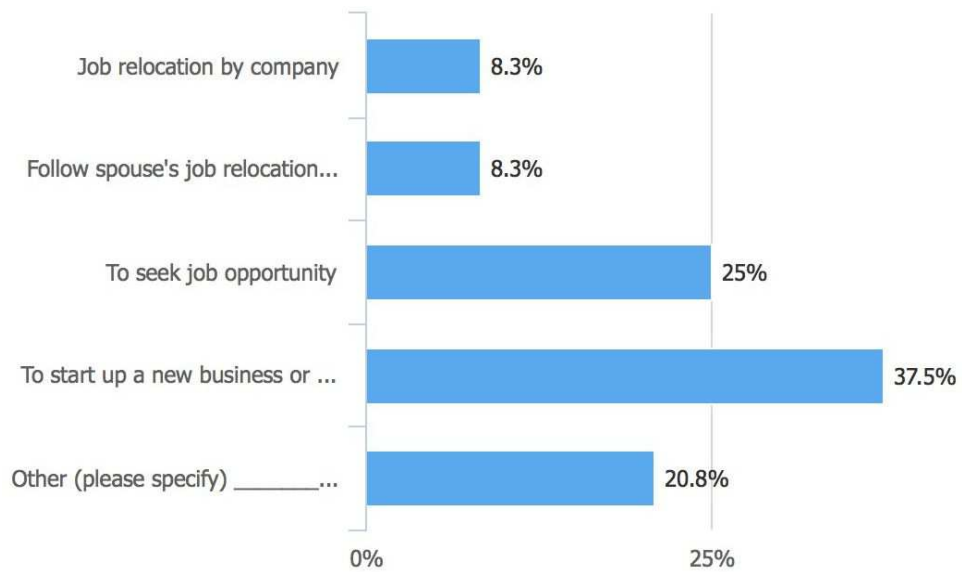

Figure 2. Reason to come to China

Source: own elaboration. 


\section{Mostly More Senior, Highly Educated and Have Working Experience Prior China}

About $75 \%$ of the survey participants had jobs (54.2\%) or were entrepreneurs (20.8\%) prior to their coming to China, similarly to the four interviewees. Specifically in the survey, of those who came to China to 'seek job opportunity' and 'startup a new business', more than a half of them had had jobs or were entrepreneurs before coming to China; this accounted for over $88 \%$ - especially those that had come to China for the purpose of starting up a new business (Figure 3), showing that foreign women entrepreneurs in China are more experienced. Over $66 \%$ of them were middle or senior managers before coming to China to startup businesses.

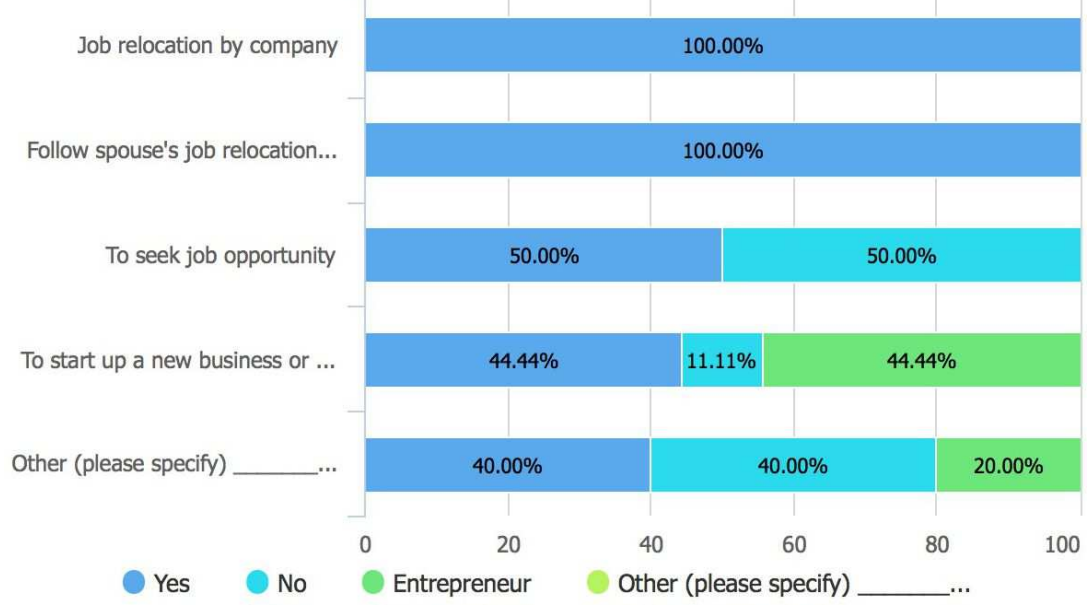

Figure 3. Prior employment status vs. reason to come to China Source: own elaboration.

The age range of the interviewees is 31 to 62 years old. The result of the survey showed that the age range of 25-35 prevailed amongst those who had originally come to China to seek job opportunities. However, the age range of those who had come to China to startup a new business was more diverse, but the majority were 36 to 55 years old (Figure 4), i.e., they were older than the respondents cited in GEM's WER 2016/2017 report.

All four interviewees are highly educated women; they either have a bachelor's or a master's degree. The survey respondents confirmed the same. The survey results show that over $91 \%$ of them have a diploma or above, over $83 \%$ are either at an undergraduate or master's level. A similar situation was found with many other research findings where female entrepreneurs are highly educated or relatively highly educated (e.g., GEM WER 2016/2017 report; Ascher, 2012; Lee \& Marvel, 2014). Apparently, foreign women entrepreneurs in China tend to be highly educated, more mature and have more experience. 


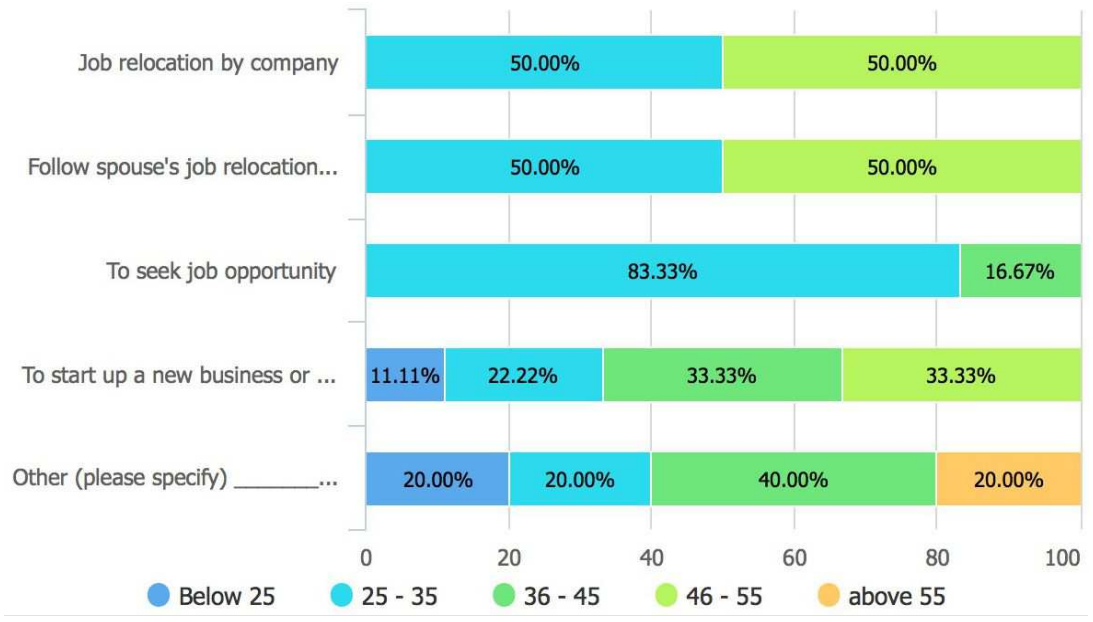

Figure 4. Age vs. Original Reason to come to China Source: own elaboration.

\section{Industry Sectors are the Same for Female Entrepreneurs Across Countries}

Although four of the interviewees were working in different industries, three are actually in the service sector, with only a small number of employees. Their challenges lay mainly in the difficulty to scale up because of the specific business nature. The fourth was in the traditional male-dominated manufacturing sector with about 50 employees, but hers was a family inherited business, so does not reveal her real interest in running the business. In fact, she did not see herself to be running that business for long. If given a chance, she would like to have her own business exploring future lifestyle of community, living and housing.

The business natures of these four foreign women entrepreneurs are in line with the findings of existing studies and reviews, that women tend to run smaller businesses (De Vita et al., 2014) and are mostly in service sectors, especially in retail and healthcare sectors (Davis \& Abdiyeva, 2012; De Vita et al., 2014; Lee \& Marvel, 2014; Li et al., 2017). Our survey results backed up these findings. Most of the businesses of our survey respondents were in professional and personal services (over $41 \%$ ) and then followed by the healthcare (16.7\%) and retail (8.3\%) sectors. Scholars have come up with a variety of arguments to explain this phenomenon, namely education, risk-averseness and life quality or the preference to balance family and business (Lee \& Marvel, 2014; Gomes, Santana, Araújo, \& Fontes-Martins, 2014). Although the issue requires further study, it does appear that these characteristics are inherent to women entrepreneurs no matter where they are.

\section{Scalability Issue and Most of Them Are Early Stage Startup Businesses}

All our interviewees mentioned the challenge of business scalability. Itv-3 described her observation of regular foreign women entrepreneurs in her network and had a similar conclusion. She pointed out that their business is usually smaller in scale and difficult to scale up either because of the business nature or the difficulty to find local partners; most of them are either in fashion, food and beverage, consulting or coaching, types of soft business. Itv-1 said 'most female foreign entrepreneurs do not build business to scale or 
in a long term. It is usually more likely that they have something to occupy their time with while here, but not to pay the rent'. On the other hand, Itv-4 noticed from her entrepreneurs' network that local Chinese women entrepreneurs also tend to run smaller businesses and they get directly involved in detailed operations.

Our survey outcome is also in line with the observation and finding of the interviewees and those reported by other studies. They noted that female foreign entrepreneurs tend to run smaller businesses. The majority of their businesses have 10 or fewer employees (over $87 \%$ ) with self-employed dominating at $45.8 \%$. Besides, $45.8 \%$ of their business performance has an annual revenue of less than USD 10,000 and overall, more than $91 \%$ of their businesses have less than USD 500,000 annual revenue; further, professional services, retail and technology sectors have the highest annual revenue (Table 3 ).

Table 3. Industry Sector vs. Annual Revenue

\begin{tabular}{|c|c|c|c|c|c|c|c|c|c|c|c|c|c|}
\hline Revenue & 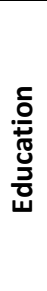 & 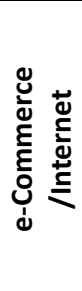 & 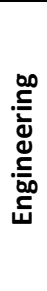 & 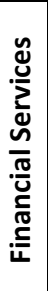 & $\underline{\underline{ }}$ & 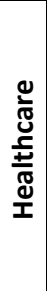 & 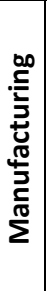 & $\frac{0}{\text { 은 }}$ & 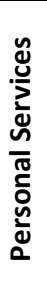 & 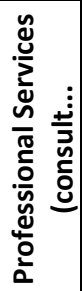 & 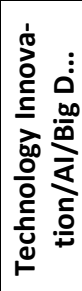 & | & '̀ \\
\hline$<$ USD10,000 & 1 & 1 & & & & 4 & 1 & 1 & 1 & 2 & & & \\
\hline$>$ USD10,000 & & & & & & & & & 1 & 2 & & & 1 \\
\hline$>$ USD50,000 & & & & & & & & & & 2 & & & \\
\hline$>$ USD100,000 & & & & & & & & & & $\underline{\underline{1}}$ & $\underline{1}$ & $\underline{2}$ & $\underline{1}$ \\
\hline$>$ USD500,000 & & & & & & & & & & $\underline{1}$ & & & \\
\hline \multicolumn{14}{|l|}{ >USD1 million } \\
\hline >USD10 millions & & & & & & & & & & & & & $\underline{1}$ \\
\hline \multicolumn{14}{|l|}{$>$ USD100 millions } \\
\hline >USD1billion & & & & & & & & & & & & & \\
\hline
\end{tabular}

Source: own study.

Only two businesses have over USD 500.000 annual revenue and they were established 17 or more years ago. Most of them with business size less than USD 500.000 were early stage businesses because over $81 \%$ of these businesses were established only three years ago or less than that.

\section{Opportunity and Entrepreneurship Environment in China Are Key Drivers}

This could possibly be explained by the fact that women entrepreneurs got the encouragement to startup a business in China only in recent years. This was possible due to the entrepreneurial spirit and a favourable environment driven by the Chinese government since 2014 . Indeed, all of the interviewees explicitly mentioned about the greater opportunity due to the market size and the advanced mobile technologies, as well as very strong entrepreneurship spirit in China. The survey results also indicated similar views that most foreign women entrepreneurs come to China to startup businesses because of greater opportunities and the entrepreneurial business environment. This accounts for a total of $62.5 \%$ (Figure5). 


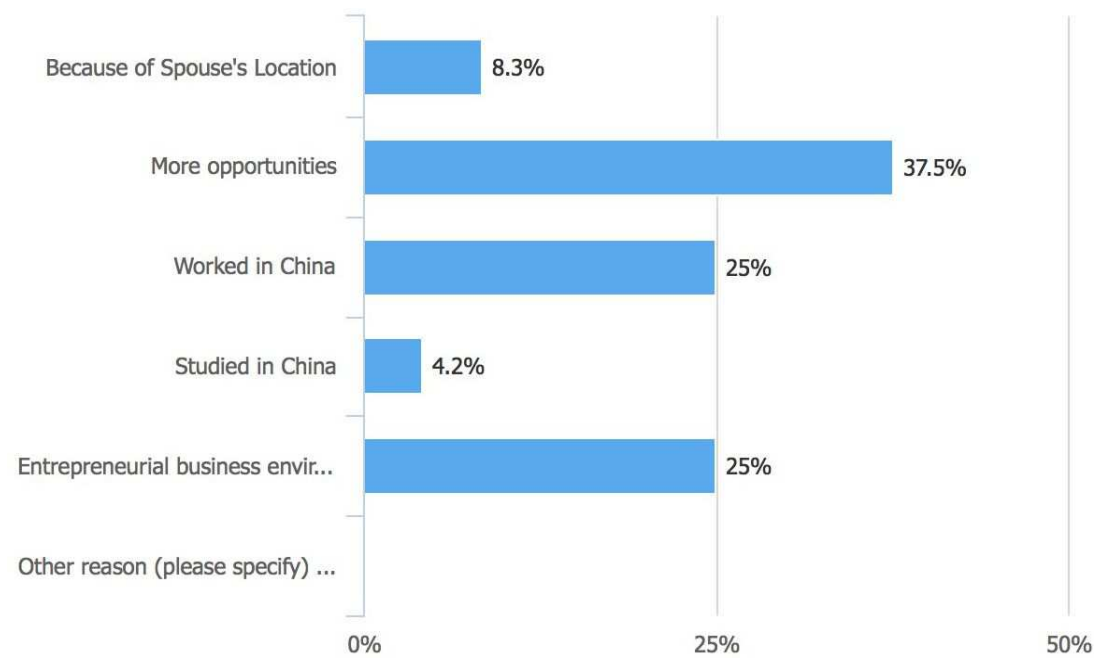

Figure 5. Reason to startup a business in China

Source: own elaboration.

Moreover, over $83 \%$ of them even confirmed that they would recommend their female foreign friends to start a business in China. The huge market opportunity was described by almost all of them as the key reason for this recommendation.

\section{Funding Sources and Barriers Appear to be Common Internationally}

Funding is critical for any new start-up business. Our survey has found that 'personal saving' is the number one funding source followed by 'family and friends', whilst 'bank loan' and ' $\mathrm{VC} / \mathrm{PE}$ ' are least considered as startup funding (Table 4).

Table 4. Funding Source

\begin{tabular}{|l|c|c|c|c|c|c|}
\hline \multirow{2}{*}{\multicolumn{1}{|c|}{ Finding Sources }} & \multicolumn{7}{c|}{ Priority } \\
\cline { 2 - 8 } & $\mathbf{1}$ & $\mathbf{2}$ & $\mathbf{3}$ & $\mathbf{4}$ & $\mathbf{5}$ & N/A \\
\hline Personal Saving & $\underline{\mathbf{1 8}}$ & 1 & 1 & 2 & 2 & 0 \\
\hline Family and Friends & 1 & $\underline{\mathbf{6}}$ & 2 & 2 & 6 & 7 \\
\hline Bank Loan & 2 & 1 & 1 & 2 & 2 & $\underline{\mathbf{1 6}}$ \\
\hline VC / PE & 3 & 1 & 0 & 4 & 2 & $\underline{\mathbf{1 4}}$ \\
\hline Other & 3 & 0 & 1 & 1 & 3 & $\underline{\mathbf{1 6}}$ \\
\hline
\end{tabular}

Source: own study.

This is consistent with most research and literature review findings that women tend to use personal savings or borrow from family and friends instead of seeking a formal external financial source to startup a business (Gomes et al., 2014; Lee \& Marvel, 2014; Li, Zhang, \& Yang, 2010). This is possibly because women face more difficulties in accessing external financing or they simply do not seek it, they are more reluctant to take risks, or prefer to use less capital for the startup (Lee \& Marvel, 2014; Gomes et al., 2014; 
Fernandes \& Mota-Ribeiro, 2017). Our survey has also shown that 'difficulty of acquiring investment or financial funding' is among the biggest challenges that foreign female entrepreneurs face (Table 5). This seems to be typical for women entrepreneurs no matter where they are. Nevertheless, a more comprehensive study in this area is recommended because startup capital and further financing has a significant impact on both the scalability and sustainability of business.

Table 5. Top 3 Challenges/Barriers

\begin{tabular}{|l|c|c|c|c|}
\hline \multicolumn{1}{|c|}{ Top 3 Challenges } & $\mathbf{1}$ & $\mathbf{2}$ & $\mathbf{3}$ & N/A \\
\hline Lack of experiences and skills & 1 & 7 & 5 & 11 \\
\hline Difficulty of acquiring investment or financial funding & 6 & 4 & 7 & 7 \\
\hline Lack of business social capital or network & 6 & 9 & 2 & 7 \\
\hline Family Obligation and Lack of time & 2 & 2 & 4 & 16 \\
\hline gender discrimination & 1 & 1 & 6 & 16 \\
\hline Cultural differences & 7 & 5 & 3 & 9 \\
\hline Business scalability & 7 & 3 & 8 & 6 \\
\hline Talent attraction and retention & 5 & 4 & 4 & 11 \\
\hline Others (pls specify) & 0 & 0 & 0 & 24 \\
\hline
\end{tabular}

Source: own study.

\section{Gender Discrimination Seems not to Be a Major Issue in China}

Gender discrimination is often the result of gender beliefs that are culturally inherent to a society and a possible explanation for reducing women's likelihood of entering entrepreneurship (Minniti \& Naudé, 2010). However, most of the interviewees said that China (particularly Shanghai) is a great place for female entrepreneurs.

Itv-2 '... a great opportunity in Shanghai. Rated one of the best cities for female entrepreneurs...'

Itv-3 '... China doesn't have barriers like other countries, female entrepreneurs have lots of opportunities, especially Shanghai women are very independent...'

Itv-4 '... environment for female leaders in Shanghai is a lot more positive than expected, female leaders in Shanghai have a relatively good position compared to Europe; especially females of my generation in Shanghai, maybe even more powerful than men because they have no limits to think. It is easier for me to tell people in Shanghai that I am the CEO of a company. Even in Europe, which is known for gender equality, people would question how it is possible for a young girl to be CEO. In China, this is not a surprise...'

Again, the survey outcome confirms a similar finding as in Table 5 which indicates that 'gender discrimination' is the least difficult barrier to cross in China. A Mexican survey participant also mentioned specifically that 'financial trust and business with women' makes it easier to start a business in China.

However, there is still a diverse and mixed opinion toward this. This could also be industry specific. For example, as pointed out by Itv-4, her business is a male-dominated traditional manufacturing business in China and the former owner and management are all men. So her 
greatest frustration concerns the industry's expectation from a traditional male leader as opposed to that from a young lady. A recent empirical study about entrepreneurial identity transition concluded that women entrepreneurs running family businesses try their best to fit into a masculine society. Also, the main goal of a women business owner is to gain respect in the 'men's world' as exemplified by former male management. This stems from the urge to become recognized by the family and workers (Fernandes \& Mota-Ribeiro, 2017).

While answering the survey question on what the key challenges were as the foreign women entrepreneurs in China, around $29 \%$ still described several gender discrimination aspects as their key challenges, e.g., 'some males in the industry do not take you seriously', 'to recognize and listen to you', 'they (men) want to do business with men, they (men) don't trust that as women we have the knowledge and expertise', 'being perceived as pushy rather than aggressive and committed-these are adjectives often reserved for men', etc. On the other hand, there are actually a few of them experiencing a positive gender advantage rather than discrimination for being female foreign entrepreneurs. This could be very industry specific, so there is a need for an empirical study using a larger sample.

\section{Greater Difficulty in Doing Business in China}

Although both our interview and survey findings have pointed to the greater opportunity and bigger market in China attracting entrepreneurs, most of the participants observed that it was more difficult to start a business in China. Itv-1 commented on the local administrative challenges, such as regulations, human resources, taxes and accounting etc., being a lot more complex in China. Itv-4 emphasized the talent acquisition challenge, market understanding, language barrier, cultural challenge and trust issue.

Our survey found that $54.2 \%$ participants think it is more difficult to do business in China. The most mentioned reasons for being difficult was legal and administrative complexity followed by culture and language barriers, and then market understanding. Those who thought that it was easier to start a business in China stated that the reasons were mainly market opportunity and entrepreneurial spirit and activity.

Indeed, China actually ranks 78th out of 190 countries in the World Bank Ease of Doing Business Rating as reported in the latest GEM 2017/2018 report (GEM, 2018). Female foreigners first come to China to startup a business, focusing to capture the greater opportunity there but ignoring the specific uniqueness of the Chinese ease of doing business in China is a major challenge.

\section{Cultural Difference is a Big Challenge and also an Opportunity for Great Learning}

The interviewees commented that Chinese people's willingness to try and not to be afraid to fail, as well as adaptability are good qualities of Chinese people. One of the survey participants resonated a similar comment and stated that the "higher speed of development of new ideas and willingness to try out these new ideas' makes it easier to do business in China. The foreign women entrepreneurs positively perceived this entrepreneurship spirit to be embedded in Chinese culture. However, the culture difference is still the major challenge for foreigners and foreign women entrepreneurs.

Women entrepreneurs have largely been found to be more people-centric in their leadership style (Davis \& Abdiyeva, 2012). China has a strong people-oriented culture, even foreigners doing business here would find that a leadership style has to be peopleoriented in order to be more effective in business operations and achieving business goals. 
Itv-4 recounted a typical story, illustrating how a foreign profit-oriented culture needs to be adjusted to adapt to the local cultural norms.

'... when I first came here, I was very focused on sales with our sales team, numbers, KPI - these were my goals that we have to achieve, this is our strategy, how to get there etc...it would be ok, but it would be much more effective if I could actually focus on goals and numbers apart from focusing just on the people involved. So sometimes if I felt like our sales people were not delivering for whatever reasons, first I would remind them of the goal: hey you are not delivering, what's the reason, this is our goal, you only do 60\%; a very much number focused. And then I realized that by completely dropping the numbers, and just calling my sales employees in the evening and asking them is everything ok? Is there anything I can do to help or support you? I found this to be far more effective than just talking about these goals...'

From the survey finding, as indicated in Table 5, 'culture difference' is the highest among the top three challenges and barriers selected. Besides, $25 \%$ of the survey participants also described in their language that culture (12.5\%) and language $(12.5 \%)$ are their key challenges in doing business in China.

\section{Patience/Adaptability/Flexibility/Resilience are the Most Common Learning}

Itv-4 stated that 'Chinese are extremely adaptive and that the number one skill for the future world is adaptability because everything will be so uncertain in the future.' Our survey outcome also agreed with this. 'Patience', 'adaptability', 'flexibility' and 'resilience' are among the most common elements worthy of learning from China.

However, when it comes to the question about any good practices or innovation or policy or culture of China that can be imbibed in foreign countries, $37.5 \%$ of did not have any opinions or were unsure. Only $25 \%$ mentioned technology and innovation, followed by $12.5 \%$ who described government support policies. It appears that it is still too early for most foreign women entrepreneurs to comment on the learning; they do not have yet enough experience with major influential aspects from China that could be diffused internationally.

\section{Mentor and Supports are Important in Entrepreneurship in China}

Over $75 \%$ of foreign women entrepreneurs had mentors and supporters to inspire or guide them during their startup processes. Over one third had a mixture of Chinese and foreign mentors but the majority (37.5\%) were just foreign mentors. In either way, this indicated that most of them are leveraging social resource and network to support their entrepreneurship which is important as suggested by Minniti and Naudé (2010). However, the reasons cited did not relate to gender differences.

\section{DISCUSSION AND FUTURE RESEARCH}

Over $85 \%$ of the participants of the interview and survey are from developed economies, it is actually not a surprise to see majority of their typology as 'success-oriented' or 'strongly success-oriented' that is also confirmed by their motivation factor to entrepreneurship as 'self-achievement' and 'autonomy and independence'. While many past research suggested a strong relationship between family responsibility and women entrepreneurship, the survey 
result does not agree that family factor played a significant role in their motivation and was an obstacle to entrepreneurship. The opportunity driven nature of these female foreigners to enter entrepreneurship in China is likely one of the key reasons. Opportunity entrepreneurship has a significantly positive impact on economic development (Acs, 2006), but the difficulty of doing business in China rated as the key issue by the interviewees and survey participants might likely hinder the potential economic growth.

Besides, our interviews and survey presented a possible link of scalability with business nature and the number of startup years, but larger scale empirical research is highly recommended to understand what factors confine the business natures of female foreign entrepreneurs and how they compare with male entrepreneurs given the variety of opportunities and technology advancement available in China.

Although cultural difference was still regarded as one of the most challenging barriers, the relatively low gender discrimination could be one of the key reasons for making China more attractive to female foreign entrepreneurs. China could possibly play a key role in demoting gender discrimination and contribute to fostering female entrepreneurship globally.

Foreign women entrepreneurs can gain a lot in terms of developing personal skills and capability growth by doing business in China. Qualities like patience, adaptability, flexibility and resilience were mentioned by our respondents to be the factors contributing the most to personal development. That could be applicable to any other country. However, few shared specifically any external learning like good practices, technology, innovation, policy etc. from China that can be diffused internationally. The reasons for this seem to lie in the early-stage and the nature of industrial sectors of their startup businesses in China. This is also an area deserving further study; whether gender plays a different role in this aspect or not should be valuable in terms of the overall understanding of women entrepreneurship.

This research has reached many conclusions similar to those from many past studies in other countries. The similarities involve mostly external factors, such as the nature of the business, industry sector, business size, business performance, financing, as well as challenges and barriers. But the cultural difference has clearly stood out as additional major barrier for foreign women entrepreneurs in China. More in-depth and larger scale empirical research is highly recommended to provide practical insights for the policy maker to unleash the full potential of the economy by including and supporting these highly motivated and opportunity-driven foreign women entrepreneurs.

As for internal factors such as motivation and family-business orientation, the findings from this research are at variance from previously reported opinions. Female foreign entrepreneurs start businesses in China mainly for self-accomplishment, greater independence and autonomy. Likewise, family/work balance is not a major factor. Having attained high education levels and being a lot more experienced, the majority of them are essentially 'strongly success-oriented'. They cited greater opportunities provided by China as well as the entrepreneurial spirit and environment prevailing there as the main reasons for this. Furthermore, there is relatively lower gender discrimination in China; it is even lower than that in the so-called equal-opportunity countries like the European countries. All these make it easier for female foreign entrepreneurs to consider starting up a business in China. 


\section{CONCLUSIONS}

The research result shows many similarities between the foreign female entrepreneurs we studied and those reported in past studies. Most of the similarities lie in external factors such as business nature, scale, sectors and performance as well as their challenges and barriers such as financing. However, there were also differences in terms of internal factors such as motivation, especially family obligation and family-business orientation. Though gender discrimination was surprisingly lower in China as mentioned by the participants, culture is still regarded as the biggest challenge to them. However, the most common learning from China they reported was also related to culture, the Chinese qualities, such as adaptability, flexibility, resilience, etc. Most foreign women entrepreneurs also found them a greater difficulty in doing business in China when compared to their home country or other foreign countries. These differences and challenges call for a further in-depth study if policy makers are interested in attracting these experienced and senior foreign women entrepreneurs.

Despite the obvious limitation due to the small sample size and the sample being mostly from one city only, which makes the results hard to generalise or to draw serious conclusions, our study did find out some insights about foreign female entrepreneurs in China. We found the internal and external factors that influenced their choices of starting the business, which should also enrich the overall literature on entrepreneurship, particularly women entrepreneurship in China given the high level of globalisation nowadays and China being the second largest economy in the world. We hope we have started a new line of research for colleagues working on entrepreneurship in China or cross-culturally.

\section{REFERENCES}

6th China census statistic (2010). Retrieved from http://www.stats.gov.cn/tjsj/pcsj/rkpc/6rp/html /fu05.htm on June 1, 2018.

Acs, Z. (2006). How Is Entrepreneurship Good for Economic Growth?. Innovations: Technology, Governance, Globalization, 1(1), 97-107.

Ascher, J. (2012). Female Entrepreneurship - An Appropriate Response to Gender Discrimination. Journal of Entrepreneurship, Management and Innovation, 8(4), 97-114. https://doi.org/10.7341/2012847

Bruni, A., Gherardi, S., \& Poggio, B. (2004). Entrepreneur-mentality, gender and the study of women entrepreneurs. Journal of Organizational Change Management; Bradford, 17(3), 256-268. Retrieved from http://search.proquest.com/docview/197609031/abstract/ A3AB84B5AD3A47C9PQ/1 on June 1, 2018.

Davis, P.J., \& Abdiyeva, F. (2012). En Route to a Typology of the Female Entrepreneur? Similarities and Differences Among Self-Employed Women. Journal of Management Policy and Practice, 13(4), 121-137.

De Vita, L., Mari, M., \& Poggesi, S. (2014). Women entrepreneurs in and from developing countries: Evidences from the literature. European Management Journal, 32(3), 451-460. https://doi.org/10.1016/j.emj.2013.07.009

Elston, J.A., \& Weidinger, A.K. (2015). The Role of Internationalization and Geographic Location on Entrepreneurial Intention- Empirical Evidence from China 2015.pdf. In ICSB World Conference Proceedings (pp. 1-33). International Council for Small Business (ICSB). Retrieved from https://search-proquestcom.ezproxy.nottingham.edu.cn/docview/1826918667?accountid=16676 on June 1, 2018 
Fan, X. (2012). The Status and Development Prospects of Chinese Women Entrepreneurs. Journal of Technical Economics \& Management, 2, 60-63.

Fernandes, E., \& Mota-Ribeiro, S. (2017). "Respect" and "self-determination" women entrepreneurs' identities and entrepreneurial discourses. Gender in Management: An International Journal, 32(1), 66-80. https://doi.org/10.1108/GM-04-2016-0093

GEM (2018). Global Entrepreneurship Monitor Global Report 2017/18, p. 156.

Gherardi, S. (2015). Authoring the female entrepreneur while talking the discourse of work-family life balance. International Small Business Journal, 33(6), 649-666. https://doi.org/10.1177/0266242614549780

Gomes, A.F., Santana, W.G.P., Araújo, U.P., \& Fontes-Martins, C.M. (2014). Female Entrepreneurship as Subject of Research. Review of Business Management, 319-342. https://doi.org/10.7819/rbgn.v16i51.1508

Henry, C., Foss, L., \& Ahl, H. (2016). Gender and entrepreneurship research: A review of methodological approaches. International Small Business Journal, 34(3), 217-241. https://doi.org/10.1177/0266242614549779

Kelley, D.J., Baumer, B.S., Cole, M., Dean, M., \& Heavlow, R. (2017). Women's Entrepreneurship 2016/2017 Report (p. 92). Retrieved from http://gemconsortium.org on May 28, 2018.

Lee, I.H., \& Marvel, M.R. (2014). Revisiting the entrepreneur gender-performance relationship: a firm perspective. Small Business Economics, 42(4), 769-786. https://doi.org/10.1007/s11187-013-9497-5

Lewis, K.V., Ho, M., Harris, C., \& Morrison, R. (2016). Becoming an entrepreneur: opportunities and identity transitions. International Journal of Gender and Entrepreneurship, 8(2), 98-116. https://doi.org/10.1108/IJGE-02-2015-0006

Li, J., Zhang, X., \& Yang, Z. (2010). Study on Influencing Factors and Mechanism of Industry Selection Difference When Male and Female Entrepreneurs Venture. Science of Science and Management of S.\& T., 2(31), 183-188.

Li, L., Zhong, W.G., \& Wang, Y.F. (2017). The current status of Chinese women entrepreneurs, challenges and expectation - A survey report of 2505 Chinese women entrepreneurs. Management World, 11, 50-64.

Minniti, M., \& Naudé, W. (2010). What Do We Know About The Patterns and Determinants of Female Entrepreneurship Across Countries?. The European Journal of Development Research, 22(3), 277-293. https://doi.org/10.1057/ejdr.2010.17

Noguera, M., Alvarez, C., \& Urbano, D. (2013). Socio-cultural factors and female entrepreneurship. International Entrepreneurship and Management Journal, 9(2), 183-197. https://doi.org/10.1007/s11365-013-0251-x

Patterson, N., Mavin, S., \& Turner, J. (2012). Envisioning female entrepreneur: leaders anew from a gender perspective. Gender in Management: An International Journal, 27(6), 395-416. https://doi.org/10.1108/17542411211269338

Welsh, D.H.B., Kaciak, E., \& Thongpapanl, N. (2016). Influence of stages of economic development on women entrepreneurs' startups. Journal of Business Research, 69(11), 4933-4940. https://doi.org/10.1016/j.jbusres.2016.04.055

Yadav, V., \& Unni, J. (2016). Women entrepreneurship: research review and future directions. Journal of Global Entrepreneurship Research, 6(1), https://doi.org/10.1186/s40497-016-0055-x 


\section{Authors}

The contribution share of authors is equal and amounted to $50 \%$ each of them.

\section{Kit Shun Ng}

Bachelor of Business Administration (The Chinese University of Hong Kong); Master in Global Executive MBA (The Chinese University of Hong Kong); PhD student in Strategy and Entrepreneurship (University of Nottingham, UK). Her research interests include gender and cross-culture leadership and entrepreneurship. Additionally she has worked close to 20 years, including top executive of a Fortune 500 multination corporation and local Chinese companies.

Correspondence to: Kit Shun NG, Flat 3201, Building G1, No. 1 Xue Fu, No. 666 South Qian Hu Road, Yin Zhou District, Ningbo City, Zhejiang Province, 315199, China, e-mail: pollyng123@gmail.com

\section{Ping Ping Fu}

Professor of Organizational Behaviour. She obtained her Ph.D. in Organizational Studies at the State University at Albany, New York, and has been a member of the Global Leadership and Organizational Behavioural Effectiveness (GLOBE) research project team since 1997. Her works have been published in various journals, including the Administrative Science Quarterly, Journal of International Business Studies, Journal of Organizational Behaviour, and the Leadership Quarterly. In recent years, she has been studying the influence of traditional culture on leadership.

Correspondence to: Ping Ping Fu, 199 Taikang East Road, Ningbo, 315100, China, e-mail: Pingping.Fu@nottingham.edu.cn

\section{Acknowledgements and Financial Disclosure}

The authors would like to thank all the research participants to attend the interview and provide their valuable input to the survey in a short period of time.

\section{Copyright and License}

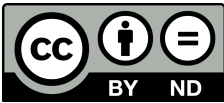

This article is published under the terms of the Creative Commons Attribution - NoDerivs (CC BY-ND 4.0) License http://creativecommons.org/licenses/by-nd/4.0/

Published by the Centre for Strategic and International Entrepreneurship - Krakow, Poland 
